\section{Citation figures suggest that the UK brain drain is a genuine problem}

Sir - Although the UK government's announcement of substantial new investment in the British science base ${ }^{1}$ was reported in the national media as being largely about stopping the 'brain drain' of researchers to the United States, previous reports had suggested that there was no firm evidence of a brain drain ${ }^{2}$. Using bibliometric data, we report here a statistically significant difference between the quality of scientists who trained in the United Kingdom but are now in the United States, and those who have stayed in the United Kingdom.

We studied a $10 \%$ stratified sample of people who obtained a doctorate in a science subject from a UK university in 1988 (ref. 3). This cohort has had sufficient time to settle into tenured or tenure-track positions, and their early publications have had time to accumulate citations.

We checked each individual researcher against the Science Citation Index (SCI) of the US Institute of Scientific Information for 1985 to 1989 and recorded the number of first-authored scientific papers published during this period, and the number of citations that each article has since received up to and including May 2000, for each individual. We used the SCI to check the publication records of individuals from 1998 to 2000 , from which we ascertained whether researchers are still active and, if so, the country in which they are based.

We analysed the data by the current country of abode to test the quality of work published a decade ago between those who are now in the United States, those in the United Kingdom and those elsewhere. Many of those in the original sample had not published an article in 1998-2000, and were omitted from the analysis. There are, of course, many reasons for not publishing, including name changes, working in industrial laboratories with non-publishing policies, career breaks, radically changing one's research area, and leaving research completely. We do not know the nationality of the scientists whose careers we have tracked, but official statistics show that people living in the UK account for a consistent fraction of approximately two thirds of people awarded doctoral degrees from UK universities ${ }^{4}$.

We found that of the 770 scientists in our sample who were awarded their doctoral degrees in 1988, 252 are known to be still publishing. This is a $33 \%$ continuation rate, and represents a minimum rate.

Of the 252 scientists we tracked, 157 $(62 \%)$ have most recently published from a UK address, 43 (17\%) from the United

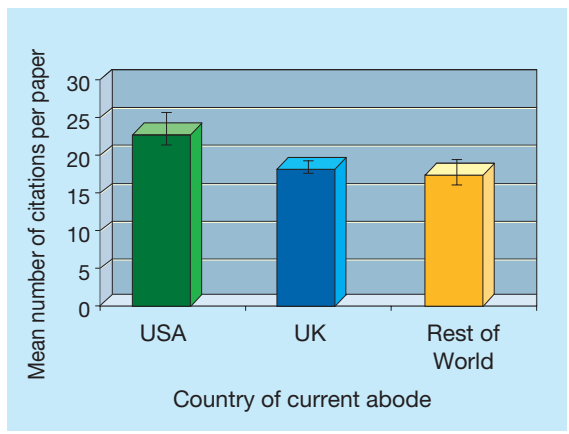

Figure 1 Mean number of citations per paper up to 2000 , for papers published in $1985-89$ by researchers with a doctoral degree from a UK university in 1988, analysed by country of current residence.

States and $52(21 \%)$ from elsewhere.

The number of articles published from 1985 to 1989 is highest for scientists now publishing from UK addresses $(2.40 \pm 0.24$ publications per person). This is not significantly higher than those now publishing from the United States (2.07 \pm 0.43$)$, but is significantly higher than those now publishing from the rest of the world $(1.15 \pm 0.24)$.

On the other hand, the mean number of citations per article for scientists who trained in the United Kingdom is significantly higher for those who are now in the United States than it is for those who remained. UK 'stayers' have more, but not significantly more, citations per paper than those currently publishing from addresses elsewhere in the world (see Fig. 1).

This is not, of course, proof of a brain drain. There are many other indications of quality than the number of citations a paper receives, and a scientist is more than the sum of his or her publications. A more thorough study of the same area is needed, which would include the nationality of individuals, a larger sample, a longer time-period, additional quality indicators and a reverse study. But our analysis so far does show that the UK government is right to regard the brain drain as a serious issue.

Alice Sharp Pierson, Peter Cotgreave

Save British Science Society, 29-30 Tavistock Square, London WC1H 9QU, UK

1. Loder, N. Nature 406, 335 (2000).

. Financial Times 1 July (2000).

Index to Theses (Aslib, London, 1990).

4. SET Statistics 1999: A Handbook of Science, Engineering and Technology Indicators (Department of Trade \& Industry, London, 1999)

\section{Debt and poverty turn a disease into an epidemic}

Sir - Many of the scientists attending the Durban conference on AIDS $^{1-4}$ have warned that South Africa's AIDS crisis can be attributed in part to President Thabo Mbeki's consultation with 'dissidents'. But are the president's words and those of his colleagues really products of denial and confusion supported by pseudoscience? President Mbeki's central point is clear: alleviating poverty and social inequalities will play a pivotal role in conquering the African AIDS crisis.

Scientists at Durban asked a reasonable question: if treatments are necessary to conquer AIDS, why hasn't President Mbeki purchased drugs? Certainly, AIDS drug costs have received considerable attention, but the lack of public-health infrastructure in Africa remains largely ignored. Why is health infrastructure so poor in these countries? The answer, again, links AIDS with poverty. World Bank figures indicate that average healthcare spending on an African person is US $\$ 14$ a year, compared with $\$ 2,673$ for the average US citizen.

In the 1960s, when public health was considered a priority by emerging independent states, investments in social spending were rewarded with declines in infant mortality and a corresponding rise in life expectancy. But by the 1980s, many African countries had plunged into an economic crisis, firmly entrenching current trends of increasing poverty, hunger and HIV infection.

Oddly, the international response to these concerns was to slash healthcare programmes as part of austerity measures called 'structural adjustment programmes' (SAPs), imposed by the World Bank and the International Monetary Fund. As the benefits of SAP-led economic growth failed to trickle down to the poor, conditions for HIV infection among native populations worsened. One example of SAPs creating the conditions that favour the spread of HIV infection is the displacement of young women to cities where they resort to commercial sex work ${ }^{5}$.

As AIDS establishes a stranglehold in South Africa, President Mbeki's government is struggling to pay more than $\$ 24$ billion to the World Bank, and thus remains unable to begin carrying out the public-health initiatives it has planned.

Given the strong correlations between poverty and AIDS, one might question the priorities of those scientists who have chosen to battle with dissident colleagues rather than making the main thrust of their campaign the epidemiology of a disease worsened by sustained indebtedness. Sanjay Basu, Kedar Mate,

Paul E. Farmer

Institute for Health and Social Justice, Department of Social Medicine, Harvard Medical School, 643 Huntington Avenue, Boston, Massachusetts 02115, USA

$$
\begin{aligned}
& \text { 1. Cherry, M. Nature 406, } 3 \text { (2000). } \\
& \text { 2. Nature 406, 15-16 (2000). } \\
& \text { 3. Cherry, M. Nature 406, } 113 \text { (2000). } \\
& \text { 4. Cherry, M. Nature 406, } 223 \text { (2000). } \\
& \text { 5. Lurie, P., Hintzen, P. \& Lowe, R. AIDS 9, 539-546 (1995). }
\end{aligned}
$$

